\title{
Why only tetraploid Solidago gigantea (Asteraceae) became invasive: a common garden comparison of ploidy levels
}

\author{
Daniel R. Schlaepfer • Peter J. Edwards • \\ Regula Billeter
}

Received: 12 March 2009/Accepted: 17 February 2010/Published online: 18 March 2010

(C) Springer-Verlag 2010

\begin{abstract}
Many studies have compared the growth of plants from native and invasive populations, but few have considered the role of ploidy. In its native range in North America, Solidago gigantea Aiton (Asteraceae) occurs as a diploid, tetraploid and hexaploid, with considerable habitat differentiation and geographic separation amongst these ploidy levels. In the introduced range in Europe, however, only tetraploid populations are known. We investigated the growth performance and life history characteristics of plants from 12 European and 24 North American (12 diploid, 12 tetraploid) populations in a common garden experiment involving two nutrient and two calcium treatments. Twelve plants per population were grown in pots for two seasons. We measured 24 traits related to leaf nutrients, plant size, biomass production and phenology as well as sexual and vegetative reproduction. Native diploid plants had a higher specific leaf area and higher leaf nutrient concentrations than native tetraploids, but tetraploids produced many more shoots and rhizomes. Diploids grown with additional calcium produced less biomass, whereas tetraploids were not affected. European plants
\end{abstract}

Communicated by Melinda Smith.

Electronic supplementary material The online version of this article (doi:10.1007/s00442-010-1595-3) contains supplementary material, which is available to authorized users.

D. R. Schlaepfer · P. J. Edwards · R. Billeter

Plant Ecology, Institute of Integrative Biology,

ETH Zurich, Zurich, Switzerland

Present Address:

D. R. Schlaepfer $(\square)$

Department of Biology, University of Wyoming,

1000 East University Avenue, Laramie, WY 82071, USA

e-mail: dschlaep@uwyo.edu were less likely to flower and produced smaller capitulescences than North American tetraploids, but biomass production and shoot and rhizome number did not differ. We conclude that a knowledge of ploidy level is essential in comparative studies of invasive and native populations. While clonal growth is important for the invasion success of tetraploid S. gigantea, its potential was not acquired by adaptation after introduction but by evolutionary processes in the native range.

Keywords Clonal growth - Invasive alien species · Polyploidy $\cdot$ Rhizome system $\cdot$ Vegetative reproduction

\section{Introduction}

One approach to understanding why some introduced plants become invasive is to compare their ecological characteristics with those of native species (e.g. Daehler 2003). This approach has been used to investigate many of the proposed attributes of successful invaders, namely, high specific leaf area (SLA), high nutrient concentrations (Daehler 2003), rapid nutrient cycling (Ehrenfeld 2003), as well as specific mechanisms, such as the enemy release (Colautti et al. 2004) and the novel weapons hypotheses (Callaway and Ridenour 2004). Another approach is to compare the growth of populations of the same species in the native range and introduced ranges (e.g. Hierro et al. 2005). In some cases, plants from invasive populations have been found to grow larger than plants from the native range (Bossdorf et al. 2005), especially in the absence of competition (Blumenthal and Hufbauer 2007) or enemies (Colautti et al. 2004); in other cases, however, no such difference has been found (e.g. Clidemia hirta, DeWalt et al. 2004; Lepidium draba, McKenney et al. 2007). Recently, considerable interest has 
focussed on the notion that these differences may have arisen through evolutionary changes in introduced populations. Such evolutionary processes may include niche shifts to exploit differing habitats in the invasive range (Broennimann et al. 2007), hybrid vigour due to mixing of previously isolated populations (Ellstrand and Schierenbeck 2000) and the evolution of increased competitive ability due to resource transfer from defence to plant growth because of enemy release (EICA, Blossey and Notzold 1995). However, despite recent research efforts, scientists still have no general understanding on where and when such evolutionary processes may have been important (Theoharides and Dukes 2007).

Solidago gigantea Aiton (Asteraceae) was introduced into Europe in 1758 (Weber and Schmid 1993) and is now invasive in a variety of habitats, including grassland, wetland and forest, on both nutrient-poor and more fertile sites (Weber and Jakobs 2005). It is a perennial herb, 0.5-2.5 m tall, with annual, partially sexual shoots and persistent, clonal rhizomes. The breeding system involves obligate outcrossing (Melville and Morton 1982). In its native range in North America, S. gigantea occurs as a diploid, tetraploid and hexaploid. Populations on the eastern side of the Appalachian Mountains and also in southern Ontario and Quebec are diploid (NA.2x). Tetraploids are found in eastern North America as far west as Missouri (NA.4x), while hexaploids occur in mid-western North America, westwards from Manitoba to the Rocky Mountains (Schlaepfer et al. 2008a; Semple and Cook 2006). In Europe, only tetraploids have been identified (EU.4x, Schlaepfer et al. 2008a).

Various adaptive and stochastic processes may account for the success of $S$. gigantea as an invasive species in Europe. First, S. gigantea has been shown to increase concentrations of nitrogen (N) (Vanderhoeven et al. 2005) and labile phosphorus $(\mathrm{P})$ in the soil (Vanderhoeven et al. 2006), probably because of higher rates of mineralization (Chapuis-Lardy et al. 2006) and organic matter turnover (Koutika et al. 2007). However, in a mesotrophic wetland lakeshore site, invasive $S$. gigantea had no impact on total soil nitrogen and phosphorus (Güsewell et al. 2005). Secondly, the closely related species $S$. canadensis has been shown to suppress arbuscular mycorrhizae in native plants (Zhang et al. 2007) and reduce the germination and establishment of seedlings (Yang et al. 2007), and it therefore seems plausible that $S$. gigantea causes similar allelopathic effects. Thirdly, introduced plants may suffer less damage from natural enemies than plants in the native range (i.e. enemy release), and there is some evidence for associated evolutionary changes. In one study, for example, invasive populations of $S$. gigantea had lower levels of certain secondary defences than native populations (Johnson et al. 2007), but not in others (Hull-Sanders et al. 2007). Also, invasive populations were more susceptible to some leaf pathogens than native populations (Meyer et al. 2005), although both compensated for insect herbivory to the same degree, albeit with different strategies (Meyer and HullSanders 2008). While evolutionary changes in response to enemy release may have contributed to the success of S. gigantea in Europe (Meyer and Hull-Sanders 2008), the evidence for EICA is far from conclusive (Güsewell et al. 2006; Meyer and Hull-Sanders 2008). Indeed, the observed differences in enemy defence and susceptibility of S. gigantea can also be explained either by stochastic processes-since only a few tetraploid haplotypes appear to have been introduced (Schlaepfer et al. 2008b) — or by deliberate selection of genotypes for their ornamental value or as nectar plants for bees (Weber and Jakobs 2005).

None of the studies of $S$. gigantea as an invasive species has taken account of ploidy level, although this factor has considerable implications for growth performance (Bretagnolle and Thompson 1996; Maceira et al. 1993), life history (Müller 1989) and plant-enemy interactions (Halverson et al. 2008; Münzbergova 2006). In the native range of $S$. gigantea, plants of different ploidy levels are mainly separated by large distances (Schlaepfer et al. 2008a), which could indicate differing habitat preferences. Support for this latter hypothesis comes from the finding that diploids occur on calcium (Ca)-poor soils whereas tetraploids appear to be insensitive to soil calcium levels, and that climatic conditions also vary among ploidy levels (Schlaepfer 2008). Additionally, geographic separation could have been caused by differences in colonization ability, a concept supported by a phytogeographic analysis of ploidy levels in North America (Schlaepfer et al. 2008b). In view of the evidence for ecological differences among ploidy levels in the native range, previous comparisons of native versus invasive populations of $S$. gigantea must be interpreted with caution.

The aims of this study were (1) to investigate whether native diploids and tetraploids differ in growth performance, life history and responses to nutrient and soil calcium treatments, (2) to relate any such differences to the habitat requirements and geographic distribution of these ploidy levels and (3) to compare the same characteristics of native and invasive tetraploids and evaluate whether evolutionary change after the introduction was also important in enabling introduced populations to become invasive.

\section{Materials and methods}

Experimental setup

In autumn 2005, we measured plant performance in the field and sampled seeds of $S$. gigantea in North America [6 NA.2x and 6 NA.4x populations per region: Southern 
Appalachian Mts. (SA, approx. $35^{\circ} \mathrm{N}$ ) and southern Ontario $\left(\mathrm{ON}\right.$, approx. $\left.45^{\circ} \mathrm{N}\right)$ ] and in Europe [6 EU.4x populations per region: northern Italy (IT, approx. $45^{\circ} \mathrm{N}$ ), and Belgium (BE, approx. $50^{\circ} \mathrm{N}$ ); Fig. 1 and Table S1 in the Electronic Supplementary Material (ESM)]. Population locations, vouchers and ploidy level determination through flow cytometry are described in Schlaepfer et al. (2008a). Seeds collected from 16 randomly chosen individual shoots per population were germinated in climate chambers, and one plant per seed-family was subsequently repotted and transferred to a cold greenhouse. To minimize possible maternal effects, experimental plants were cultivated for 4 months after germination, and all but one shoot was eliminated at the start of the experiment, so that initial biomass corresponded to $4 \%$ of the first season biomass production.

At the end of April 2006, 12 similarly sized plants per population (432 plants in total) were randomly assigned to one of four treatment combinations (fully crossed fertilizer and calcium additions, each at a low and high level; three replicates) and repotted to $7.5-\mathrm{L}$ pots in a commercial rhododendron soil (Klasmann-Deilmann, Geeste, Germany;

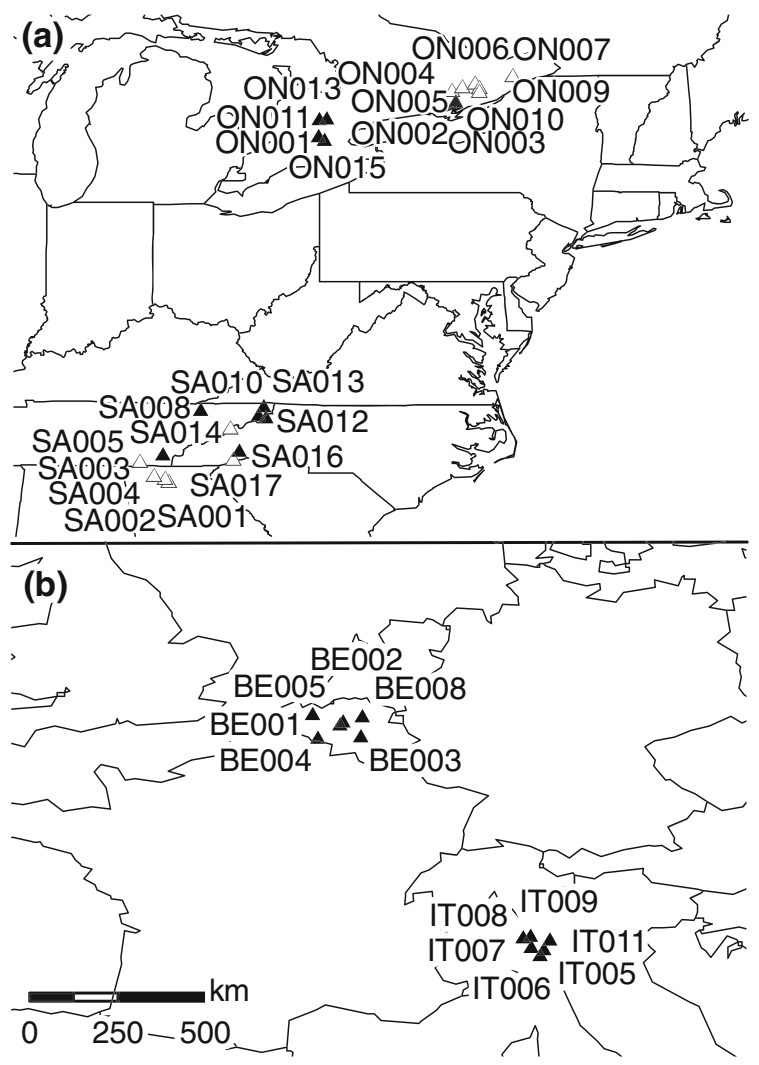

Fig. 1 Map showing the source populations of Solidago gigantea Aiton (white triangles diploid, black triangles tetraploid) used in the experiment in North America (a; SA Southern Appalachian Mts., $O N$ Ontario) and Europe (b; IT northern Italy, $B E$ Belgium). See also Table S1 in the ESM a peat-based, acid soil with low fertility). The pots were transferred to the experimental garden in Zurich (Switzerland) at $570 \mathrm{~m}$ a.s.l. To prevent edge effects, the pots were re-randomized every month until July and at the beginning of the second season.

For the nutrient treatment (two levels, low and high), a calcium-free, slow-release fertilizer was added in the first season when the plants were pricked (Osmocote exact standard 8-9 months; Scotts, Heerlen, The Netherlands). In the second season, the plants under the high nutrient level were again fertilized, this time with a commercial complete fertilizer (Wuxal; Maag Agro, Dielsdorf, Switzerland). In total, plants at the low nutrient level were supplied with $1.0 \mathrm{~g} \mathrm{~N}$ and $0.4 \mathrm{~g} \mathrm{P}$ and at the high level with $2.5 \mathrm{~g} \mathrm{~N}$ and $0.9 \mathrm{~g} \mathrm{P}$.

The calcium treatment (two levels, low and high) was administered as calcium carbonate (Sigma-Aldrich, Seelze, Germany) to the plants under the high calcium level. These plants received in total $39.8 \mathrm{~g} \mathrm{Ca}$. The plants under the low calcium level received no extra calcium. The rhododendron soil itself contained approximately $5.5 \mathrm{~g} \mathrm{Ca}$ per pot. At the end of the experiment, the soil $\mathrm{pH}$ was $3.8 \pm 0.06$ $(n=12)$ in the low calcium pots and $5.3 \pm 0.13(n=12)$ in the high calcium pots. There was a significant difference in $\mathrm{pH}$ between calcium treatment levels [analysis of variance (ANOVA) $F=131.1, p<0.001]$, but not among continents, ploidy levels or nutrient treatment levels. An additional experiment with 30 plants on a soil $\mathrm{pH}$ gradient (4-7), adjusted with sodium hydroxide, showed no effect of soil $\mathrm{pH}$ on plant biomass (ANOVA, $F=0.2, p \geq 0.942$ ).

Aphid attack was treated with Paraderil (active ingredient: rotenon; Maag Agro). Fungal attack, mostly mildew, was treated with Funginex (triforine; Maag Agro). Attack rates were low and did not differ between cytotypes (data not shown). Pathogen attack at the high nutrient level increased significantly.

In 2006, the months of May and August were wet, whereas July and the period September to November were warmer than average. In 2007, April was exceptionally hot and dry, whereas May was hot and wet. In many months it was therefore necessary to water the plants daily with (calcium-free) osmosis water.

\section{Measurements}

To control for possible differences in initial size, the experimental plants were measured at the start of the experiment (shoot number, diameter and height and leaf length and width) and pruned to a single shoot of similar size. The initial biomass of each experimental plant was estimated using allometric equations based on shoot number, leaf length and width, the square of shoot diameter and the log of plant height. The linear multiple regression was 
based on 70 additionally measured and harvested plants $\left(r_{\mathrm{adj}}^{2}=0.65, p<0.001\right)$.

During 2006, various parameters (height of tallest shoot, number of shoots and portion of shoot having senescent leaves) were recorded in May, June, July, September and at harvest in November. Any dead leaves were also collected and dried. Leaf senescence was assessed by age of the plant when $50 \%$ of shoot height was covered with dead leaves (in days after May 1). Allocation to vegetative reproduction was quantified as the percentage of non-flowering shoots. At the harvest in November 2006, the diameter of the tallest shoot and the number of latent buds visible on the soil surface were recorded ( $S$. gigantea is a hemicryptophytic species, and the number of buds provides an indication of potential vegetative reproduction). Above-ground biomass was harvested and dried at $72^{\circ} \mathrm{C}$ for 2 days before weighing (together with dead leaves).

Three healthy leaves per plant were harvested in midAugust, dried and pooled per population and treatment combination. For nitrogen and total phosphorus concentrations, samples were digested in concentrated sulphuric acid $\left(1 \mathrm{~h}\right.$ refluxing at $420^{\circ} \mathrm{C}$ with a potassium sulphatecopper sulphate Kjeltab; 2040 Digestor; Foss Tecator, Höganäs, Sweden) and analysed colorimetrically on a flow injection analyser (FIAstar 5000 Analyser; Foss Tecator). Total calcium concentrations were measured in hydrochloric acid extracts (Hunt 1982) with by atomic absorption spectroscopy (SpectrAA 240 FS; Varian AG, Zug, Switzerland). Additionally, one healthy mature mid-shoot leaf per plant was collected (Garnier et al. 2001). Leaf fresh and dry mass and area (LI-3100 Area Meter; LiCor, Lincoln, NB) were determined. SLA (ratio of leaf area to leaf dry mass) and leaf dry matter content (LDMC; ratio of leaf dry mass to fresh mass) were calculated.

To assess sexual reproduction and phenology, we checked the plants every 2-4 days during the 2006 growing season. Observations made on pollinating insects indicated that these were abundant and that pollinator flights were as frequent within ploidy levels as between them (Binomial test, $p \geq 0.383, n=21$ pollinator visits). Onset of flowering (first flower head open) and end of flowering (last flower head closed) were recorded for every shoot (capitulescence) in days after May 1. The percentage of flowering plants, number of flowering shoots, duration of flowering per plant (days between onset and end of flowering) and peak flowering per plant (date when most shoots were flowering in days after May 1) were calculated. At the end of flowering, capitulescences were clipped, dried and weighed. Capitulescence biomass and total seed production are highly correlated in S. altissima (Meyer et al. 2005). Allocation to sexual reproduction was calculated as the ratio of capitulescence biomass to total biomass.
In 2007, plants were harvested when the first flower buds appeared (beginning of June). The height of the longest shoot and number of shoots were measured, and above-ground biomass was harvested. To estimate rhizome production, we counted the rhizomes along two meridians on the outside of root balls [linear regression, $n=6$, total rhizome length $=15.4 \mathrm{~cm} \pm 1.3$ (standard error, $\mathrm{SE}$ ) $\times$ rhizome count, $\left.R^{2}=0.97\right]$. Rhizome diameter was measured on three rhizome pieces from one plant per population and treatment combination.

\section{Data analysis}

We considered the treatments as nested in the population and aggregated the data into the unit population $\times$ treatments (i.e. mean of the three replicates). Therefore, interactions were tested against populations and not against plants. Threefold and higher interactions were considered to be significant at the 0.01 level, whereas other significance levels were at 0.05 .

To test whether measured variables differed between NA. $2 \mathrm{x}$ and NA. $4 \mathrm{x}(2 x-4 x$ comparison), linear mixed models (LMM) using a restricted maximum likelihood (REML) estimator with a crossed design were used and included ploidy level, region, calcium treatment and nutrient treatment as fixed factors, population (nested within region) as a random factor and initial biomass as a covariate. Variables were transformed if needed to meet the assumptions of the model.

To test whether measured variables differed between NA.4x and EU.4x (NA-EU comparison), we used LMM with a nested design and included continent, region (nested within continent), calcium treatment and nutrient treatment as fixed factors, population (nested within region) as a random factor and initial biomass as a covariate. Only interactions with the factor continent were included (region interactions are redundant). Variables were transformed if needed to meet the assumptions of the model.

The $F$ ratio test determined the significance level of fixed factors with numerically estimated denominator degrees of freedom, whereas random factors were tested with Wald $z$ tests. For significant interactions between treatments and ploidy level or continent, responses were calculated as reaction norms, i.e. difference between means for high and low treatment level divided by the overall mean (Güsewell 2005).

We calculated coefficients of variation for each cytotype and tested for differences among cytotypes with the $\chi^{2}$ test (Zar 1999). Significance levels were adjusted with the sequential Bonferroni method (Rice 1989). All analyses were calculated with SPSS ver. 13.0.0 (SPPS, Chicago, IL). 


\section{Results}

General remarks about plant performance

All 432 plants survived the experiment and 291 flowered (Table 1). The phenology of the experimental plants was similar to that of wild populations growing nearby. In the $2 x-4 x$ comparison, diploid plants grew larger than tetraploids in the first season but not in the second (Table 2). However, in the NA-EU comparison, similar trends were obtained in both years (Table 3 ).

Both treatments affected tissue nutrient concentrations, indicating that the treatment levels were adequate to influence plant performance. The nutrient treatment significantly increased the concentration of leaf nitrogen in plants in the $2 x-4 x$ comparison [mean \pm standard deviation (SD); low treatment $1.8 \pm 0.5 \% \mathrm{~N}$, high treatment $2.0 \pm 0.6 \% \mathrm{~N}$; Table 2), although there was a similar but non-significant trend in the NA-EU comparison (low mean $1.6 \pm 0.5 \% \mathrm{~N}$, high mean $1.8 \pm 0.5 \%$ $\mathrm{N}$; Table 3). Leaf phosphorus was not significantly increased in either comparison (mean \pm SD $0.14 \pm$ $0.03 \% \mathrm{P})$. The leaf nitrogen:phosphorus ratios varied between 7 and 19, and the mean value (12.5) was significantly less than 14, suggesting that growth was limited primarily by nitrogen (Güsewell 2004), $t$ test $=$ $-7.6, p<0.001)$. The calcium treatment significantly increased leaf calcium in both comparisons (low mean $0.84 \pm 0.18 \%$ Ca, high mean $0.97 \pm 0.17 \% \quad \mathrm{Ca}$; Tables 2, 3).

\section{Variation among populations and regions}

The variation in plant performance among populations within regions was generally small, and any differences in mean parameter values were only weakly significant (Tables 2, 3). However, there was considerable variation between the two North American regions: biomass production, plant size and timing of flowering were all lower in the more northerly ON populations than in the SA ones, while leaf senescence, SLA and vegetative shoot ratio were higher (Table 2). The nutrient treatment had a stronger effect on the growth of the ON plants-significant for biomass production and shoot number-than it did for SA plants. The latitudinal trends in EU.4x were less pronounced than those for NA.4x plants, but they were broadly congruent with those in NA (Table 3): biomass production, shoot length (both second season) and timing of flowering were negatively correlated with latitude, while some reproductive traits were positively correlated.
Effects of cytotypes and cytotype-region interactions

Where coefficients of variation differed among cytotypes, diploids exhibited the largest variation (Table 1), especially for the parameters of plant growth and rhizome number. Most parameters varied significantly with ploidy level, and there were also several significant interactions between ploidy and region (Table 2). NA.4x plants differed from NA.2x plants in producing heavier leaves with a lower SLA and less nitrogen, but more shoots (Fig. 2b) and more biomass (Fig. 2c), both second season; the former also had a longer flowering period than the latter. However, by far the greatest difference between the ploidy levels was in the number of rhizomes, with a mean count of two rhizomes per pot for NA.2x plants and 16 for NA.4x plants (Fig. 3). The significant cytotype-region interactions arose because the values of several variables were higher for SA.2x than for SA.4x plants, but lower for ON.2x than for ON.4x ones or, in the case of phenological variables, the reverse of this pattern. Thus, NA.4x plants tended to vary less between regions than did NA.2x plants.

There were no significant differences between NA and EU tetraploids in terms of the number of rhizomes (Fig. 2a) and shoots (Fig. 2b) or in biomass production (Fig. 2c, Table 3). However, EU.4x plants produced more latent buds and larger leaves with a lower SLA, while NA.4x plants were taller and produced heavier capitulescences that persisted for a longer period.

\section{Responses to nutrient treatment}

Plant growth was stimulated by the addition of nutrients, with most variables responding positively to this treatment. The only parameters showing a consistently negative response were vegetative shoot ratio in the $2 x-4 x$ comparison (nutrients increased number of flowering shoots) and LDMC in the NA-EU comparison (Tables 2, 3).

The addition of nutrients affected NA.2x and NA.4x plants differently, with NA.4x plants responding more strongly than NA.2x plants in numbers of rhizomes (Fig. 2d) and latent buds and shoots (Fig. 2e), but more weakly in biomass production (Fig. 2f) and rhizome diameter. A comparison of the effect of the nutrient treatment between continents revealed that NA.4x plants responded more strongly than EU.4x plants in terms of both shoot number (Fig. 2e, second season) and duration of flowering.

Responses to calcium treatment

For both ploidy levels, the addition of calcium tended to reduce plant performance, although the effects were 
Table 1 Plant parameters $(n=24)$ measured on plants from 12 diploid, 12 North American and 12 European tetraploid populations of Solidago gigantea Aiton grown in a common garden

\begin{tabular}{|c|c|c|c|c|c|c|c|c|c|c|}
\hline \multirow[t]{4}{*}{ Variable } & \multicolumn{6}{|c|}{ Mean \pm standard error } & \multicolumn{4}{|c|}{$\begin{array}{l}\text { Coefficient of } \\
\text { variation }(\mathrm{CV})^{\mathrm{a}}\end{array}$} \\
\hline & \multicolumn{4}{|c|}{$2 x-4 x$ comparison } & \multicolumn{2}{|c|}{ NA-EU comparison } & \multicolumn{3}{|c|}{$\mathrm{CV}(\%)$} & \multirow{3}{*}{$\begin{array}{l}\chi^{2} \text { test } \\
\chi^{2} \text { value }\end{array}$} \\
\hline & \multicolumn{2}{|c|}{ S. Appalachian Mts. } & \multicolumn{2}{|l|}{ Ontario } & \multirow{2}{*}{$\begin{array}{l}\text { NA } \\
4 x\end{array}$} & \multirow{2}{*}{$\begin{array}{l}\text { EU } \\
4 x\end{array}$} & \multicolumn{2}{|l|}{$\overline{\mathrm{NA}}$} & \multirow{2}{*}{$\begin{array}{c}\overline{\mathrm{EU}} \\
4 x\end{array}$} & \\
\hline & $2 x$ & $4 x$ & $2 x$ & $4 x$ & & & $2 x$ & $4 x$ & & \\
\hline \multicolumn{11}{|l|}{ Plant growth } \\
\hline Biomass 2006 (g) & $87.5 \pm 4.5$ & $60.7 \pm 4.4$ & $26.8 \pm 1.6$ & $41.9 \pm 2.3$ & $51.3 \pm 2.8$ & $45.5 \pm 2.1$ & 61 & 38 & 31 & $17.54 * * *$ \\
\hline Biomass 2007 (g) & $58.2 \pm 5.6$ & $66.9 \pm 6.2$ & $46.6 \pm 4.8$ & $52.2 \pm 5.5$ & $59.6 \pm 4.2$ & $59.8 \pm 3.9$ & 49 & 49 & 45 & 0.34 \\
\hline Shoot diameter (mm) & $11.2 \pm 0.3$ & $8.8 \pm 0.3$ & $6.8 \pm 0.2$ & $7.5 \pm 0.2$ & $8.1 \pm 0.2$ & $7.6 \pm 0.1$ & 29 & 17 & 12 & $35.78 * * *$ \\
\hline Shoot length $2006(\mathrm{~cm})$ & $161 \pm 4$ & $134 \pm 7$ & $57 \pm 4$ & $89 \pm 3$ & $111 \pm 5$ & $87 \pm 3$ & 51 & 31 & 24 & $24.08 * * *$ \\
\hline Shoot length $2007(\mathrm{~cm})$ & $98 \pm 3$ & $83 \pm 3$ & $74 \pm 2$ & $70 \pm 3$ & $76 \pm 2$ & $69 \pm 2$ & 20 & 20 & 17 & 1.30 \\
\hline \multicolumn{11}{|l|}{ Leaf traits } \\
\hline $\begin{array}{l}\text { Age with } 50 \% \text { dead } \\
\text { leaves (days) }\end{array}$ & $121 \pm 3$ & $142 \pm 2$ & $151 \pm 2$ & $145 \pm 2$ & $144 \pm 2$ & $145 \pm 1$ & 14 & 8 & 5 & $50.87 * * *$ \\
\hline Leaf Ca $(\%)$ & $0.95 \pm 0.03$ & $0.85 \pm 0.03$ & $0.85 \pm 0.03$ & $0.9 \pm 0.04$ & $0.88 \pm 0.03$ & $0.95 \pm 0.03$ & 17 & 21 & 22 & 2.52 \\
\hline Leaf $\mathrm{N}(\%)$ & $1.7 \pm 0.1$ & $1.5 \pm 0.1$ & $2.4 \pm 0.1$ & $1.9 \pm 0.1$ & $1.7 \pm 0.1$ & $1.7 \pm 0.1$ & 26 & 32 & 28 & 1.43 \\
\hline Leaf P $(\%)$ & $0.14 \pm 0$ & $0.14 \pm 0$ & $0.17 \pm 0$ & $0.14 \pm 0.01$ & $0.14 \pm 0$ & $0.14 \pm 0$ & 17 & 17 & 19 & 1.01 \\
\hline Leaf area $\left(\mathrm{cm}^{2}\right)$ & $31.2 \pm 1.2$ & $29.1 \pm 1.1$ & $19.3 \pm 0.6$ & $24.2 \pm 1.1$ & $26.6 \pm 0.8$ & $31 \pm 1.1$ & 30 & 22 & 24 & 4.91 \\
\hline Leaf mass (mg) & $234 \pm 12$ & $245 \pm 9$ & $123 \pm 4$ & $191 \pm 10$ & $218 \pm 8$ & $263 \pm 11$ & 40 & 24 & 28 & 10.99 \\
\hline SLA $\left(\mathrm{cm}^{2} / \mathrm{g}\right)$ & $138.3 \pm 2.8$ & $121.8 \pm 2$ & $159.9 \pm 2.3$ & $130.9 \pm 1.8$ & $126.3 \pm 1.5$ & $121.9 \pm 1.7$ & 11 & 8 & 10 & 4.71 \\
\hline $\begin{array}{l}\text { LDMC (dry/fresh } \\
\text { biomass) }\end{array}$ & $0.3 \pm 0$ & $0.3 \pm 0.01$ & $0.3 \pm 0$ & $0.31 \pm 0$ & $0.31 \pm 0$ & $0.33 \pm 0$ & 5 & 7 & 6 & 6.62 \\
\hline \multicolumn{11}{|l|}{ Vegetative reproduction } \\
\hline Vegetative shoot ratio & $0.58 \pm 0.04$ & $0.75 \pm 0.03$ & $0.95 \pm 0.01$ & $0.82 \pm 0.02$ & $0.79 \pm 0.02$ & $0.94 \pm 0.01$ & 30 & 18 & 6 & $74.14 * * *$ \\
\hline Shoot number 2006 & $8 \pm 0$ & $11 \pm 1$ & $12 \pm 0$ & $10 \pm 1$ & $11 \pm 0$ & $12 \pm 0$ & 30 & 29 & 29 & 0.00 \\
\hline Shoot number 2007 & $10 \pm 0$ & $16 \pm 1$ & $12 \pm 1$ & $19 \pm 2$ & $17 \pm 1$ & $19 \pm 1$ & 31 & 37 & 31 & 1.61 \\
\hline Rhizome number & $3 \pm 1$ & $12 \pm 1$ & $0 \pm 0$ & $20 \pm 2$ & $16 \pm 1$ & $12 \pm 1$ & 168 & 57 & 61 & $29.21 * * *$ \\
\hline Rhizome diameter (mm) & $5 \pm 0.2$ & $4.6 \pm 0.2$ & $4.1 \pm 0.2$ & $3.8 \pm 0.1$ & $4.2 \pm 0.1$ & $4.2 \pm 0.1$ & 25 & 20 & 18 & 5.42 \\
\hline \multicolumn{11}{|l|}{ Sexual reproduction } \\
\hline $\begin{array}{l}\text { Flowering plants } \\
(\% \text { of all })\end{array}$ & $0.97 \pm 0.02$ & $0.82 \pm 0.05$ & $0.39 \pm 0.06$ & $0.88 \pm 0.03$ & $0.85 \pm 0.03$ & $0.49 \pm 0.05$ & 54 & 24 & 67 & $26.01 * * *$ \\
\hline $\begin{array}{l}\text { Flowering shoots } \\
\text { per plant }\end{array}$ & $2.6 \pm 0.2$ & $2.7 \pm 0.5$ & $1.3 \pm 0.1$ & $1.6 \pm 0.2$ & $2.2 \pm 0.3$ & $1.2 \pm 0.1$ & 49 & 82 & 36 & $20.75 * * *$ \\
\hline Sexual mass ratio & $0.12 \pm 0.01$ & $0.07 \pm 0.01$ & $0.09 \pm 0.02$ & $0.23 \pm 0.01$ & $0.15 \pm 0.01$ & $0.08 \pm 0.01$ & 66 & 62 & 86 & 2.89 \\
\hline $\begin{array}{l}\text { Capitulescence } \\
\text { biomass (g) }\end{array}$ & $11.2 \pm 1.1$ & $5.1 \pm 0.8$ & $4.7 \pm 0.7$ & $10.3 \pm 0.8$ & $7.7 \pm 0.7$ & $5.2 \pm 0.7$ & 67 & 61 & 85 & 2.85 \\
\hline $\begin{array}{l}\text { Flowering duration } \\
\text { (days) }\end{array}$ & $50 \pm 2$ & $51 \pm 3$ & $29 \pm 2$ & $48 \pm 2$ & $50 \pm 2$ & $36 \pm 2$ & 36 & 24 & 29 & 6.54 \\
\hline $\begin{array}{l}\text { Age at peak flowering } \\
\text { (days) }\end{array}$ & $144 \pm 2$ & $156 \pm 2$ & $134 \pm 2$ & $117 \pm 3$ & $137 \pm 3$ & $134 \pm 3$ & 7 & 17 & 14 & $28.34 * * *$ \\
\hline
\end{tabular}

Significance levels were sequential Bonferroni adjusted: *** $p<0.001$, $* * p<0.01$

$N A$ North America, EU Europe, $L D M C$ leaf dry matter content, $S L A$ surface leaf area

${ }^{\text {a }}$ Coefficient of variation $(\mathrm{CV})$ of each cytotype and $\chi^{2}$-tests for differences among cytotypes

generally small (Tables 2, 3). However, there were reductions in the numbers of rhizomes (Fig. $2 \mathrm{~g}$ ), latent buds and shoots (Fig. 2h, second season), shoot diameter and LDMC (this effect being stronger for SA than for ON).
Only for SLA were the effects of added calcium significantly positive (Table 2). Similar effects were found in the between-continent comparisons (Table 3), with numbers of rhizomes (Fig. 2g) and shoots (Fig. 2h, second season), 


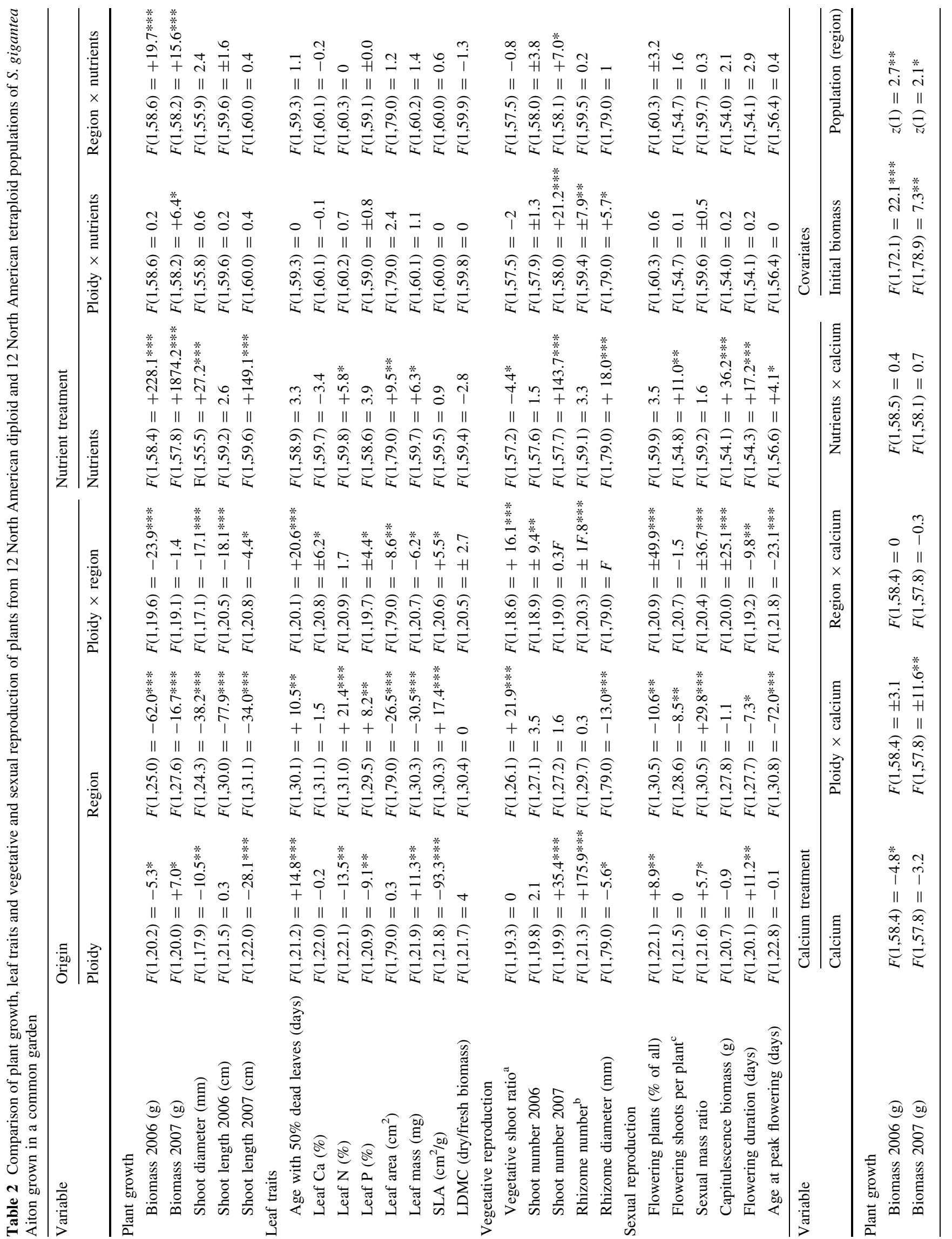




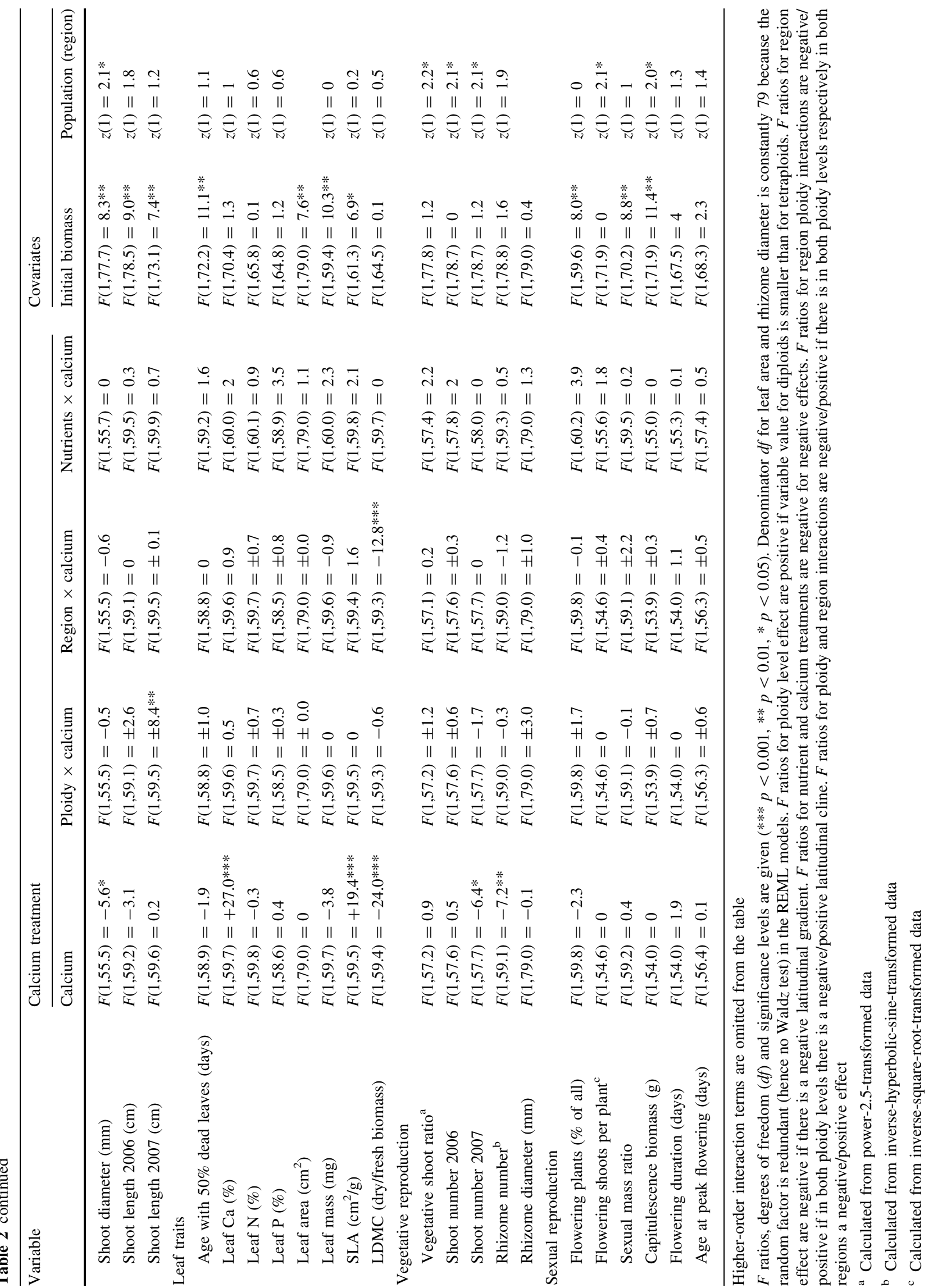




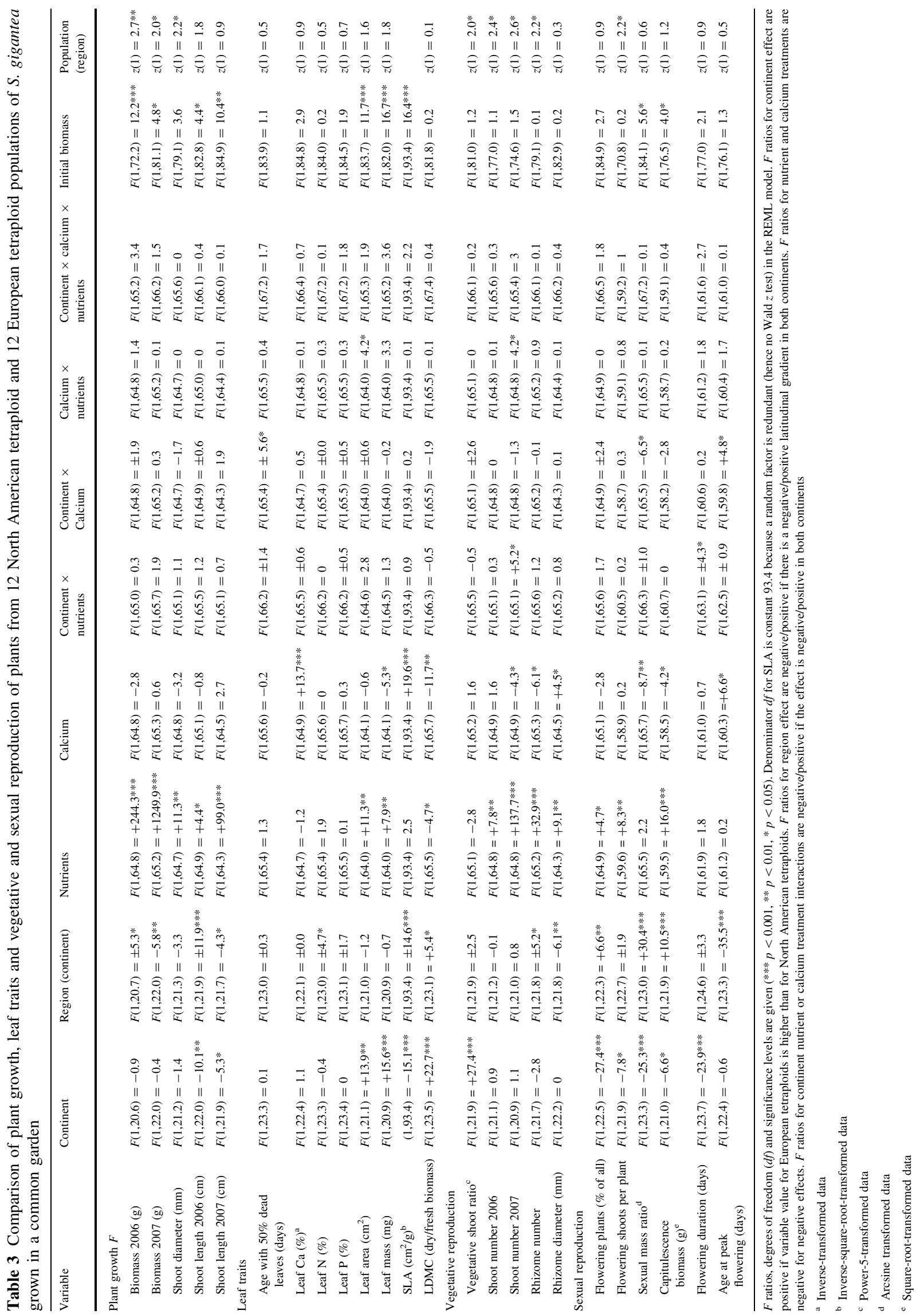


capitulescence biomass, leaf mass and LDMC being significantly reduced by the addition of calcium, whereas SLA and rhizome diameter increased.

There were significant differences between ploidy levels in their reponse to added calcium (Table 2): while NA.2x plants responded negatively in the second season for biomass production (Fig. 2i) and shoot height, NA.4x plants were either indifferent or responded positively. Between continents, calcium significantly decreased the sexual mass ratio of EU.4x plants and postponed flowering time and leaf senescence, whereas NA.4x plants were indifferent to the calcium treatment (Table 3 ).

\section{Discussion}

The experimental plants were similar in size and phenology to those in wild populations. We cannot exclude the possibility that 'maternal' effects influenced our results, especially in the first season (Roach and Wulff 1987), although we attempted to minimize these by cultivating the plants for several months before the experiment. In the case of NA.2x plants, germination time and first season biomass were correlated $(r=-0.31, p<0.034)$, which could reflect a maternal effect. However, in a previous common garden experiment with the same species (Güsewell et al. 2006), correlations with field parameters were obtained, and these results were clearly due to genetic rather than maternal effects. Whenever possible, here we focus the discussion on growth variables available from the second season, since these are less likely to be affected by any maternal effects.

There were clear differences in the performance of diploid and tetraploid plants of S. gigantea, and also between plants of the same ploidy level in different regions. These regional differences in time of flowering and plant size, which were found for both native and invasive populations, likely reflect clinal variation associated with latitude and are comparable to results from an earlier study with invasive $S$. gigantea (Weber and Schmid 1998). Similar latitudinal clines in both native and invasive populations have also been found in a number of other species, including Hypericum perforatum (Maron et al. 2004). For S. gigantea, however, latitudinal clines were less congruent between native and invasive tetraploids than between diploid and tetraploid native populations. This result suggests that the populations in the introduced range have not yet adapted fully to local conditions, either because there has not been sufficient time (although other studies have demonstrated rapid adaptation in introduced populations of this species; Weber and Schmid 1998) or because of the limited genetic diversity in invasive populations (Schlaepfer et al. 2008b).
In addition to latitudinal variation, we detected strong interactions between region of origin and ploidy level in native populations, with diploids being more genetically distinct between regions than tetraploids (Schlaepfer et al. $2008 \mathrm{~b}$ ). The greater differentiation and genetic variation of diploids is also reflected in a higher coefficient of variation for many parameters than was obtained for tetraploids.

Soil calcium as growth modifier of $S$. gigantea

The calcium treatment affected plant development in all cytotypes, reducing the numbers of shoots and rhizomes and increasing SLA. However, there were also differences in the responses of the cytotypes to increased soil calcium, with NA.2x plants tending to reduce growth in the second season. This effect was probably not due to altered $\mathrm{pH}$, since a small additional experiment showed $S$. gigantea plants to be relatively insensitive to $\mathrm{pH}$. It is also unlikely to have been due to reduced phosphorus availability in the calcium treatment, since the nitrogen:phosphorus ratios suggest that nitrogen was the more limiting nutrient. We suppose, therefore, that the result was a direct effect, albeit small, of higher calcium concentrations.

Physiological differentiation between ploidy levels in response to calcium has been found in other studies. Tetraploid Isatis indigotica, for example, expresses higher levels than its diploid counterpart of the calcium-dependent protein kinase gene IiCPK2, which is active in various pathways including responses to cold, high salinity and certain hormones (Lu et al. 2006). Our results may indicate links between such physiological differentiation in calcium response and habitat differentiation observed in wild populations, with NA.2x tending to show a calcifuge behaviour that was not evident in NA.4x (Schlaepfer 2008).

Pre-disposition of tetraploid S. gigantea

for colonization

Previous studies have shown varying effects of ploidy upon plant performance and life history. In some cases, no effects were detected, such as for Aster amellus (Münzbergova 2007) and Ranunculus adoneus (Baack and Stanton 2005), while in others, differences between ploidy levels were considerable, as in Arrhenatherum elatius (Petit and Thompson 1997), Dactylis glomerata (Bretagnolle and Thompson 1996) and Centaurea maculosa (Müller-Schärer et al. 2004).

Solidago gigantea is among those species in which differences between ploidy levels are considerable, especially in the life history traits. Diploids show functional characteristics associated with more rapid growth and a shorter life span than tetraploids. Thus, the largest shoots obtained in our experiment were of NA.2x plants in the first 
Fig. 2 Differences of $S$. gigantea cytotypes (NA.2x, white bars North American diploid, NA.4x, grey bars North American tetraploid, EU.4x, black bars, European tetraploid) in response to nutrients $(\mathbf{d}-\mathbf{f})$ and calcium (g-i) in the second season for rhizome number (a), shoot number (b) and aboveground biomass (c). Bars indicate mean \pm standard error (SE). Response values indicate reaction norms for significant interactions between treatments and cytotypes, calculated as the difference between means for the high and low treatment level divided by the overall mean (Güsewell 2005). Homogeneous subsets are based on linear mixed models and on Dunnett T3 post hoc tests (Tables 2, 3)
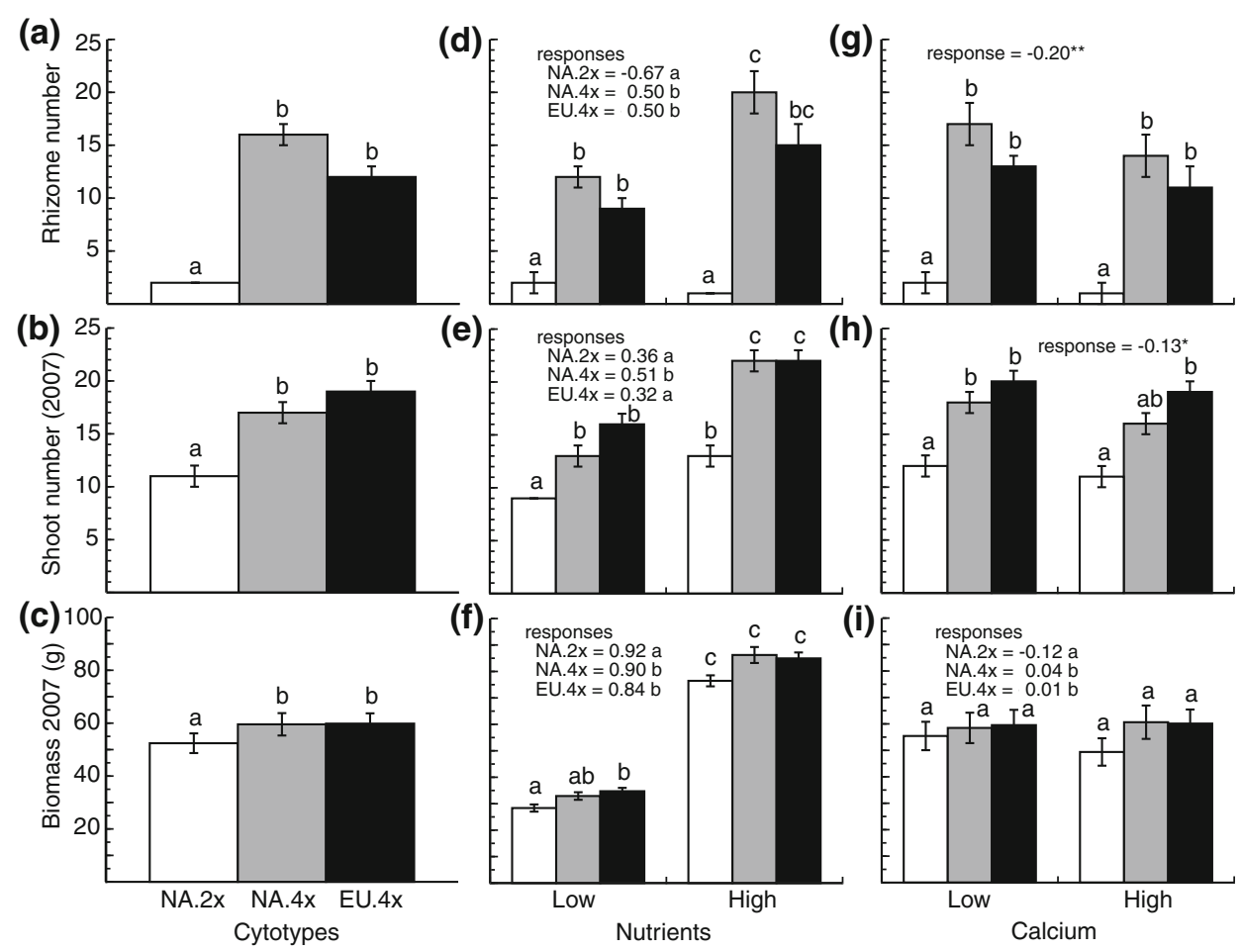

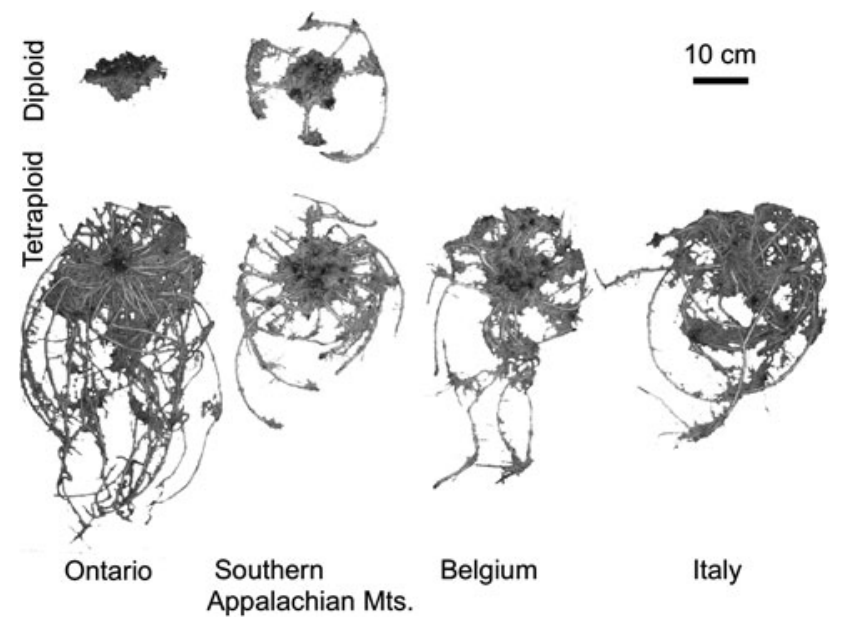

Fig. 3 Variation of the rhizome system between ploidy levels and between regions of origin of S. gigantea. All rhizomes (and some residual roots) are from plants grown under the high nutrient treatment, without the calcium addition treatment

season, with a biomass of $163 \mathrm{~g}$, a height of $2.2 \mathrm{~m}$ and a shoot diameter of $2.0 \mathrm{~cm}$. The NA.2x plants have generally high values for leaf nitrogen and SLA, a combination that is characteristic of fast-growing species (Reich et al. 1999; Shipley et al. 2005). Similarly, NA.2x has a high allocation of biomass to shoots rather than to rhizomes. However, the diploids also showed a wider range of growth performance than NA.4x plants and greater differentiation among regions.
On the other hand, NA.4x plants appear to be a longerlived, clonal perennial with a much larger rhizome system than the diploid ones. This, in turn, is reflected in more shoots being produced, which could explain why the plant biomass of NA.4x overtook that of NA.2x in the second year. These results support the hypothesis that NA.4x plants were able to extend their range in North America because of their superior colonizing ability, such as a welldeveloped rhizome system, and broader ecological niche (e.g. tolerance to calcium; Schlaepfer 2008).

\section{Invasive tetraploid populations of $S$. gigantea}

Studies that have investigated whether introduced populations of S. gigantea exhibit increased plant performance and competitive ability have produced conflicting results. A field study found supportive results (Jakobs et al. 2004), while experimental studies, including the one reported here, found no consistent increase in plant height or biomass in invasive populations compared to native populations (Meyer et al. 2005; Meyer and Hull-Sanders 2008). However, compared to native plants, invasive $S$. gigantea plants have been found to produce more shoots through clonal growth (Güsewell et al. 2006) and to allocate more resources to rhizomes than to flowers (Meyer and HullSanders 2008), although they were less likely to flower (Meyer and Hull-Sanders 2008). Our results support the finding that invasive populations are less likely to flower and they invest less biomass into flowers, but the 
differences we obtained for shoot and rhizome number were not significant. Although the differing results may partly reflect the locations of the common garden experiments (Maron et al. 2004), it is likely that previous studies included both diploid and tetraploid plants from the native range. Given the considerable differences between ploidy levels, this may explain the large variation found in some of the earlier studies.

The ability of $S$. gigantea to invade dense, established vegetation and nutrient-poor sites (Weber and Jakobs 2005) has been attributed to its clonal growth (Güsewell et al. 2006). Furthermore, this ability seems not to be restricted to the invasive range but applies also to tetraploids in the native range (Schlaepfer 2008). The relatively poor colonizing ability of diploids could be one reason why diploids are absent from Europe. Our ploidy-level precise comparison suggests that the vigorous rhizome system of tetraploid $S$. gigantea is one factor that contributes to its invasion success, in addition to other factors not investigated here, such as enemy release, evolutionary changes, founder effects and allelopathy. Therefore, comparative studies should take care to compare like genotypes with like (Dlugosch and Parker 2008). Even though genetic change may be detected in invasive populations, the potential to become invasive is not necessarily acquired in the introduced range but may be a property of particular genotypes in the native range (Bastlova et al. 2004; Hooftman et al. 2006). The fact that the vigorous rhizome growth of S. gigantea is not unique to invasive populations-but rather to polyploids of this species-supports this hypothesis.

Acknowledgments We thank Sabine Güsewell for statistical advice, Martin Fotsch for help with the experiment, Philipp Streckeisen for his efforts in the greenhouse (FAL, Reckenholz, Switzerland), Andreas Wolf for measuring leaf traits and Rose Trachsler for nutrient analyses. We also thank Jake Alexander, Daniela Eichenberger, Harry Eggenschwiler, Min Hahn, Edith Lang, Myriam Poll, Carmen Rothenbühler, Rodolphe Schlaepfer and Mila Trtiková for help during the harvest. The project is funded by the grant 0-20259-05 from the ETH Zurich, Switzerland. The experiments comply with the current laws of the country in which they were performed.

\section{References}

Baack EJ, Stanton ML (2005) Ecological factors influencing tetraploid speciation in snow buttercups (Ranunculus adoneus): niche differentiation and tetraploid establishment. Evolution 59:19361944

Bastlova D, Cizkova H, Bastl M, Kvet J (2004) Growth of Lythrum salicaria and Phragmites australis plants originating from a wide geographical area: response to nutrient and water supply. Glob Ecol Biogeogr 13:259-271

Blossey B, Notzold R (1995) Evolution of increased competitive ability in invasive nonindigenous plants-a hypothesis. J Ecol 83:887-889
Blumenthal DM, Hufbauer RA (2007) Increased plant size in exotic populations: A common-garden test with 14 invasive species. Ecology 88:2758-2765

Bossdorf O, Auge H, Lafuma L, Rogers WE, Siemann E, Prati D (2005) Phenotypic and genetic differentiation between native and introduced plant populations. Oecologia 144:1-11

Bretagnolle F, Thompson JD (1996) An experimental study of ecological differences in winter growth between sympatric diploid and autotetraploid Dactylis glomerata. J Ecol 84:343351

Broennimann O, Treier UA, Müller-Schärer H, Thuiller W, Peterson AT, Guisan A (2007) Evidence of climatic niche shift during biological invasion. Ecol Lett 10:701-709

Callaway RM, Ridenour WM (2004) Novel weapons: invasive success and the evolution of increased competitive ability. Front Ecol Environ 2:436-443

Chapuis-Lardy L, Vanderhoeven S, Dassonville N, Koutika LS, Meerts P (2006) Effect of the exotic invasive plant Solidago gigantea on soil phosphorus status. Biol Fertil Soils 42:481-489

Colautti RI, Ricciardi A, Grigorovich IA, MacIsaac HJ (2004) Is invasion success explained by the enemy release hypothesis? Ecol Lett 7:721-733

Daehler CC (2003) Performance comparisons of co-occurring native and alien invasive plants: Implications for conservation and restoration. Annu Rev Ecol Evol S 34:183-211

DeWalt SJ, Denslow JS, Hamrick JL (2004) Biomass allocation, growth, and photosynthesis of genotypes from native and introduced ranges of the tropical shrub Clidemia hirta. Oecologia 138:521-531

Dlugosch KM, Parker IM (2008) Founding events in species invasions: genetic variation, adaptive evolution, and the role of multiple introductions. Mol Ecol 17:431-449

Ehrenfeld JG (2003) Effects of exotic plant invasions on soil nutrient cycling processes. Ecosystems 6:503-523

Ellstrand NC, Schierenbeck KA (2000) Hybridization as a stimulus for the evolution of invasiveness in plants? Proc Natl Acad Sci USA 97:7043-7050

Garnier E, Shipley B, Roumet C, Laurent G (2001) A standardized protocol for the determination of specific leaf area and leaf dry matter content. Funct Ecol 15:688-695

Güsewell S (2004) N:P ratios in terrestrial plants: variation and functional significance. New Phytol 164:243-266

Güsewell S (2005) Responses of wetland graminoids to the relative supply of nitrogen and phosphorus. Plant Ecol 176:35-55

Güsewell S, Zuberbühler N, Clerc C (2005) Distribution and functional traits of Solidago gigantea in a Swiss lakeshore wetland. Bot Helvetica 115:63-75

Güsewell S, Jakobs G, Weber E (2006) Native and introduced populations of Solidago gigantea differ in shoot production but not in leaf traits or litter decomposition. Funct Ecol 20:575-584

Halverson K, Heard SB, Nason JD, Stireman JO (2008) Differential attack on diploid, tetraploid, and hexaploid Solidago altissima L. by five insect gallmakers. Oecologia 154:755-761

Hierro JL, Maron JL, Callaway RM (2005) A biogeographical approach to plant invasions: the importance of studying exotics in their introduced and native range. J Ecol 93:5-15

Hooftman DAP, Oostermeijer JGB, den Nijs JCM (2006) Invasive behaviour of Lactuca serriola (Asteraceae) in the Netherlands: Spatial distribution and ecological amplitude. Basic Appl Ecol 7:507-519

Hull-Sanders HM, Clare R, Johnson RH, Meyer GA (2007) Evaluation of the evolution of increased competitive ability (EICA) hypothesis: Loss of defense against generalist but not specialist herbivores. J Chem Ecol 33:781-799

Hunt J (1982) Dilute hydrochloric acid extraction of plant material for routine cation analysis. Commun Soil Sci Plant Anal 13:49-55 
Jakobs G, Weber E, Edwards PJ (2004) Introduced plants of the invasive Solidago gigantea (Asteraceae) are larger and grow denser than conspecifics in the native range. Divers Distrib 10:11-19

Johnson RH, Hull-Sanders HM, Meyer GA (2007) Comparison of foliar terpenes between native and invasive Solidago gigantea. Biochem Syst Ecol 35:821-830

Koutika LS, Vanderhoeven S, Chapuis-Lardy L, Dassonville N, Meerts P (2007) Assessment of changes in soil organic matter after invasion by exotic plant species. Biol Fertil Soils 44:331341

Lu BB, Ding RX, Zhang L, Yu XJ, Huang BB, Chen WS (2006) Molecular cloning and characterization of a novel calciumdependent protein kinase gene IiCPK2 responsive to polyploidy from tetraploid Isatis indigotica. J Biochem Mol Biol 39:607617

Maceira NO, Jacquard P, Lumaret R (1993) Competition between diploid and derivative autotetraploid Dactylis glomerata L. from Galicia-implications for the establishment of novel polyploid populations. New Phytol 124:321-328

Maron JL, Vila M, Bommarco R, Elmendorf S, Beardsley P (2004) Rapid evolution of an invasive plant. Ecol Monogr 74:261-280

McKenney JL, Cripps MG, Price WJ, Hinz HL, Schwarzlander M (2007) No difference in competitive ability between invasive North American and native European Lepidium draba populations. Plant Ecol 193:293-303

Melville MR, Morton JK (1982) A biosystematic study of the Solidago canadensis (Compositae) complex. 1. The Ontario populations. Can J Bot 60:976-997

Meyer GA, Hull-Sanders HM (2008) Altered patterns of growth, physiology and reproduction in invasive genotypes of Solidago gigantea (Asteraceae). Biol Invas 10:303-317

Meyer G, Clare R, Weber E (2005) An experimental test of the evolution of increased competitive ability hypothesis in goldenrod, Solidago gigantea. Oecologia 144:299-307

Müller H (1989) Growth pattern of diploid and tetraploid spotted knapweed, Centaurea maculosa Lam. (Compositae), and effects of the root mining moth Agapeta zoegana (L.) (Lep.: Cochylidae). Weed Res 29:103-111

Müller-Schärer H, Schaffner U, Steinger T (2004) Evolution in invasive plants: implications for biological control. Trends Ecol Evol 19:417-422

Münzbergova Z (2006) Ploidy level interacts with population size and habitat conditions to determine the degree of herbivory damage in plant populations. Oikos 115:443-452

Münzbergova Z (2007) No effect of ploidy level in plant response to competition in a common garden experiment. Biol J Linnean Soc 92:211-219

Petit C, Thompson JD (1997) Variation in phenotypic response to light availability between diploid and tetraploid populations of the perennial grass Arrhenatherum elatius from open and woodland sites. J Ecol 85:657-667
Reich PB, Ellsworth DS, Walters MB, Vose JM, Gresham C, Volin JC, Bowman WD (1999) Generality of leaf trait relationships: A test across six biomes. Ecology 80:1955-1969

Rice WR (1989) Analyzing tables of statistical tests. Evolution 43:223-225

Roach DA, Wulff RD (1987) Maternal effects in plants. Annu Rev Ecol Syst 18:209-235

Schlaepfer DR (2008) Ecological significance of ploidy level of native and invasive populations of Solidago gigantea. $\mathrm{PhD}$ thesis no. 17677. ETH, Zurich. Available at: http://e-collection.ethbib. ethz.ch/view/eth:30868

Schlaepfer DR, Edwards PJ, Semple JC, Billeter R (2008a) Cytogeography of Solidago gigantea (Asteraceae) and its invasive ploidy level. J Biogeogr 35:2119-2127

Schlaepfer DR, Edwards PJ, Widmer A, Billeter R (2008b) Phylogeography of native ploidy levels and invasive tetraploids of Solidago gigantea (Asteraceae). Mol Ecol 17:5245-5256

Semple JC, Cook RE (2006) Solidago. In: Flora of North America Editorial Committee (ed) Flora of North America North of Mexico, vol 20. Magnoliophyta: Asteridae, part 7: Asteraceae, part 2: Asterales, part 2. Oxford University Press, Oxford/New York, pp 107-166

Shipley B, Vile D, Garnier E, Wright IJ, Poorter H (2005) Functional linkages between leaf traits and net photosynthetic rate: reconciling empirical and mechanistic models. Funct Ecol 19:602-615

Theoharides KA, Dukes JS (2007) Plant invasion across space and time: factors affecting nonindigenous species success during four stages of invasion. New Phytol 176:256-273

Vanderhoeven S, Dassonville N, Meerts P (2005) Increased topsoil mineral nutrient concentrations under exotic invasive plants in Belgium. Plant Soil 275:169-179

Vanderhoeven S, Dassonville N, Chapuis-Lardy L, Hayez M, Meerts P (2006) Impact of the invasive alien plant Solidago gigantea on primary productivity, plant nutrient content and soil mineral nutrient concentrations. Plant Soil 286:259-268

Weber E, Jakobs G (2005) Biological flora of central Europe: Solidago gigantea Aiton. Flora 200:109-118

Weber E, Schmid B (1993) Das Neophytenproblem. Diss Bot 196:209-227

Weber E, Schmid B (1998) Latitudinal population differentiation in two species of Solidago (Asteraceae) introduced into Europe. Am J Bot 85:1110-1121

Yang RY, Mei LX, Tang JJ, Chen X (2007) Allelopathic effects of invasive Solidago canadensis L. on germination and growth of native Chinese plant species. Allelopathy J 19:241-247

Zar JH (1999) Biostatistical analysis, 4th edn. Prentice Hall, Upper Saddle River

Zhang Q, Yao LJ, Yang RY, Yang XY, Tang JJ, Chen X (2007) Potential allelopathic effects of an invasive species Solidago canadensis on the mycorrhizae of native plant species. Allelopathy J 20:71-77 